\title{
O ser mestre nos dias de hoje: uma breve reflexão
}

\section{To be a teacher in the present time: a brief reflection}

\author{
El ser maestro en la actualidad: una breve reflexión
}

\section{Claudia Barbosa Teixeira*}

\begin{abstract}
RESUMO
A docência no ensino superior é um tema vasto e tem gerado um número significativo de pesquisas, artigos e livros. O presente artigo tem como objetivo suscitar a reflexão sobre o papel do professor universitário que, nos dias de hoje, possui, no mínimo, o título de mestre. Analisando três, dos vários significados do vocábulo mestre, teceu-se considerações sobre o ofício do professor e suas atribuições, baseando-se em educadores que se debruçaram sobre o assunto. Propõe-se, ao final do artigo, um modelo de mestre, apresentando sua metodologia que poderá servir de base para aqueles que pretendem seguir tão nobre missão.

Palavras-chave: Mestre; Universidade; educação.
\end{abstract}

\begin{abstract}
Teaching in higher education is a vast subject and has generated a significant number of research, articles and books. The purpose of this article is to stimulate reflection on the role of the university professor, who at present has at least the title of master. Analyzing three of the various meanings of the word teacher, a number of considerations were made about the craft of the teacher and his attributions based on educators who studied the subject. It is proposed, at the end of the article, a master model, presenting its methodology that may serve as a basis for those who intend to follow such a noble mission.
\end{abstract}

Keywords: Master; University; education.

\section{RESUMEN}

La docencia en la enseñanza superior es un tema vasto y ha generado un número significativo de investigaciones, artículos y libros. El presente artículo tiene como objetivo suscitar la reflexión sobre el papel del profesor universitario, que en los días de hoy, posee como mínimo el título de maestro. Al analizar tres de los varios significados del vocablo maestro, se teceran consideraciones sobre el papel del profesor y sus atribuciones basándose en educadores que se inclinaron sobre el asunto. Se propone, al final del artículo, un modelo de maestro, presentando su metodología que podrá servir de base para aquellos que pretenden seguir tan noble misión.

Palabras clave: Maestro; Universidad; educación.

* Arquiteta e Urbanista. Mestre em Arquitetura e Urbanismo pela Universidade Federal Fluminense e doutora em História Política pela Universidade do Estado do Rio de Janeiro. Professora do Programa de Pós-Graduação em História da Arte Sacra da Faculdade São Bento (Rio de Janeiro/RJ). 


\section{Introdução}

"Os que tiverem sido inteligentes fulgirão como o brilho do firmamento, e os que tiverem introduzido muitos nos caminhos da justiça luzirão como as estrelas, com um perpétuo resplendor". (Dn 12, 3).

Há anos, os alunos tinham por hábito chamar os professores de "mestres". Ao longo do tempo, este costume foi desaparecendo. Atualmente se denomina "mestre" àquele que tem mestrado, assim como "doutor", ao que tem doutorado. Um profissional que estiver cursando pós-graduação, provavelmente, em dois anos, receberá o título de mestre, se tudo correr de acordo com o planejado. Fica, então, o questionamento sobre o que significa tal titulação e o que acontece "da noite para o dia" em que se torna "mestre". Existe uma expressão popular que diz: "quem sabe faz, quem não sabe, ensina”. Entretanto, é reconhecido que o papel do mestre é de saber e de saber fazer. Na pesquisa realizada sobre Educação, para elaboração desse artigo, percebe-se que esta reflexão se estende a docentes de diversas áreas do saber, que se preocupam com o papel do mestre-professor e suas atribuições. Pimenta e Anastasiou (2002) citam que:

Os pesquisadores dos vários campos do conhecimento e os profissionais de várias áreas adentram o campo de docência no ensino superior como decorrência natural dessas suas atividades e por razões e interesses variados. Se trazem consigo imensa bagagem de conhecimentos nas suas respectivas áreas de pesquisa e de atuação profissional, na maioria das vezes nunca se questionaram sobre o que significa ser professor. Do mesmo modo, as instituições que os recebem já dão por suposto que o são, desobrigando-se, pois, de contribuir para torná-los (PIMENTA; ANASTASIOU, 2002, p. 104).

Estas autoras, como tantos outros, mergulharam na árdua tarefa de estabelecer critérios, parâmetros, meios, pilares, diretrizes, enfim, toda a sorte de pesquisas e estudos sobre o profissional do ensino. E muitos também se aprofundaram nas questões relacionadas aos recém-mestres que se tornam professores. Ser mestre, certamente, não significa apenas ter um título. Mas, o que é ser mestre? O que difere o mestre do professor? O que significa ser mestre nos dias de hoje? Como desenvolver o perfil de um mestre?

\section{O que é ser mestre}

Inicialmente, a fim de desenvolver melhor o conceito de mestre, recorreu-se ao dicionário, em busca do seu significado. Dentre tantas definições, foram escolhidas três, por estarem diretamente correlacionadas à questão do ensino propriamente dito: "Aquele que ensina, professor"; "Indivíduo 
superior e de muito saber"; "Aquele que tem o mestrado".

\section{"Aquele que ensina, professor"}

Como se pode observar, mestre e professor são sinônimos. Aquele que ensina, por vezes, deixa de cumprir seu papel de educador, passando a ser um repetidor de conhecimentos. Ensinar, certamente, significa muito mais do que "passar conhecimento". Se fosse só isso, aquele que ensina seria apenas um reprodutor de conteúdos estabelecidos ou de livros didáticos. Ensinar é guiar, informar, formar, capacitar, levar o outro a descobrir seu próprio caminho. Ensinar é querer ver nos olhos dos alunos o brilho do "eu quero saber mais sobre isso".

"Ensinar não é transferir conhecimento, mas criar as possibilidades para a sua produção ou a sua construção" (FREIRE, 1996, p. 22). E mais: é se expor, revelar, entregar, atualizar. E questionar. Questionar, sempre. Um mestre não pode achar que já sabe tudo. Ou acreditar que determinada maneira de ensinar deu certo e nunca mais tentar outras. É estar em formação permanente.

Pimenta e Anastasiou (2002) confirmam a preocupação com a capacitação dos educadores, demonstrando seu papel fundamental junto à sociedade: "Os professores têm um grande trabalho a realizar, que é proceder à mediação entre a sociedade da informação e os alunos, a fim de possibilitar que, pelo exercício da reflexão, adquiram a sabedoria necessária à permanente construção do humano" (PIMENTA; ANASTASIOU, 2002, p. 102).

E um professor, a despeito do que o levou a exercer essa função, deveria sentir, acima de tudo, como qualquer outro profissional, alegria e prazer naquilo que faz, possibilitando que sua presença em sala de aula despertasse nos alunos o respeito e a paixão por aquilo que ensina. De acordo com Einstein (1981):

É tarefa essencial do professor, despertar a alegria de trabalhar e de conhecer. [...] Pensem em todas as maravilhas, objetos de seus estudos, são a obra de muitas gerações, uma obra coletiva que exige de todos um esforço entusiasta e um labor difícil e impreterível. Tudo isso, nas mãos de vocês, se torna uma herança. Vocês a recebem, respeitam-na, aumentam-na e, mais tarde, irão transmiti-la fielmente à sua descendência. Deste modo, somos mortais imortais, porque criamos juntos obras que nos sobrevivem. Se refletirem seriamente sobre isso, encontrarão um sentido para a vida e para o seu progresso. E o julgamento que fizerem sobre os outros homens e as outras épocas será mais verdadeiro (EINSTEIN, 1981, p. 31-32).

\section{"Indivíduo superior e de muito saber"}

A princípio, o conceito de um indivíduo superior e de muito saber nos remete a um profissional respeitado, valorizado humana e financeiramente. Geralmente, um homem/mulher deste perfil guarda para si seu conhecimento 
e superioridade, pois é dessa forma que detém o poder. Mas o verdadeiro mestre nada contra a maré, pois a ele cabe compartilhar seu conhecimento, suas habilidades, sua cultura, seu saber. Ao mestre interessa instigar seus alunos a ir mais adiante. Ir além das fronteiras estabelecidas.

Em sala de aula, por vezes, ouve-se a reclamação dos alunos a respeito daquele professor ou professora que é bem sucedido em sua carreira profissional, autor ou autora de diversos livros, mas que, ao entrar em contato com a classe, repete o conteúdo de suas publicações, assumindo que todos já as conheceram e entenderam o conteúdo ali demonstrado. Não há abertura para questionamentos, dúvidas. Aos alunos resta o silêncio respeitoso. Ignorar a falta de perguntas em sala de aula não deveria ser a atitude de um mestre. Aquele que muito sabe respeita aquele que vivencia o processo de aprendizagem. Afinal, esse processo inclui ambas as partes.

Urge que a humildade entre em cena, sob pena da sala de aula se transformar num palco onde se apresenta um monólogo do professor. Estar atento às demandas de seus alunos deveria ser a preocupação daquele ou daquela que tanto investiu no seu próprio conhecimento. A respeito da capacidade intelectual daquele que ensina, Freire (1996) aponta que:

a rigorosidade, a séria disciplina intelectual, o exercício da curiosidade epistemológica não me fazem necessariamente um ser mal-amado, arrogante, cheio de mim mesmo. Ou, em outras palavras, não é a minha arrogância intelectual a que fala de minha rigorosidade científica. [...] Não nego a competência, por outro lado, de certos arrogantes, mas lamento neles a ausência de simplicidade que, não diminuindo em nada seu saber, os faria gente melhor. Gente mais gente (FREIRE, 1996, p.146).

$\mathrm{O}$ verdadeiro indivíduo superior e de muito saber não se sente ameaçado pelos seus alunos, nem pelos seus pares, pois ele sabe que se ajudar alguém a alçar um voo maior do que o seu, cumpriu sua missão.

\section{"Aquele que tem o mestrado"}

Aquele que tem o mestrado é, hoje, um forte candidato a uma vaga de professor universitário, se assim o desejar. A exigência de titulação nas universidades é demonstrada no Decreto 2.207/97, que estabeleceu que, a partir do segundo ano de sua vigência, as instituições de ensino superior deveriam contar com 15\% de seus docentes titulados na pós-graduação strictu sensu; no quinto ano de vigência com $25 \%$; e no oitavo ano com um terço (PIMENTA; ANASTASIOU, 2002). A partir de então, o que se observou é que, efetivamente, houve um aumento de demanda por cursos de pós- 
-graduação nas universidades.

Tal fato é comprovado pelas informações contidas no site do Plano Nacional de Educação, ${ }^{1}$ onde se registra que, no ano de 2014 , a porcentagem de mestres e doutores no corpo docente das instituições de Ensino Superior era de $74,3 \% .^{2}$ Ou seja, os números indicam que foi ultrapassado significativamente o índice estabelecido pelo decreto de 1997. Ainda de acordo com o PNE, a meta é alcançar 75\% do percentual de mestres e doutores em efetivo exercício até o ano de 2024. A justificativa para essa taxa, segundo os termos do Plano, se baseia na ideia de que:

Um dos passos mais importantes para garantir um Ensino Superior de qualidade é ter um bom quadro de profissionais dando aulas. Aumentar a quantidade de mestres e doutores dando aula nas universidades e faculdades brasileiras, inclusive no setor privado, é um desafio para garantirmos o melhor aprendizado para os alunos. ${ }^{3}$

Como contratado ou concursado, um profissional com título de mestre estaria habilitado para ministrar aulas. Mas, será que os dois anos de especialização fazem do profissional um especialista em matéria de ensino?

O que há em comum entre os diversos artigos pesquisados sobre o tema é que o fato do profissional possuir competência sobre determinado assunto não faz dele um transmissor de conhecimento competente. Pimenta e Anastasiou (2002) apontam que, embora o professor tenha ingressado na universidade pelo cargo da docência, são raras as oportunidades que tem de se aperfeiçoar nesse aspecto, tanto no mestrado como no doutorado. As autoras argumentam que, via de regra, esses novos professores recebem da instituição ementas prontas e não são orientados quanto a processos de planejamento, metodológicos ou avaliatórios. Enfim, o recém-mestre/professor se vê em sala de aula diante de um grande desafio.

\footnotetext{
O Plano Nacional de Educação é uma lei ordinária sancionada no ano de 2014, determinada pelo artigo 214 da Constituição Federal de 1988, que estabelece diretrizes, metas e estratégias de concretização no campo da Educação. Além disso, há estratégias específicas para a redução da desigualdade e inclusão de minorias, como alunos com deficiência, indígenas, quilombolas, estudantes do campo e alunos em regime de liberdade assistida. A partir da promulgação do PNE, todos os planos estaduais e municipais de Educação devem ser criados ou adaptados em consonância com as diretrizes e metas estabelecidas pelo PNE. Universalização e ampliação do acesso a uma Educação de qualidade, assim como garantia de permanência dos alunos em todos os níveis educacionais, formação inicial e continuada de professores e profissionais da Educação, melhorias nas condições de trabalho que tornem a carreira docente mais atraente e aumento do financiamento público da Educação são alguns dos principais pontos considerados pelo PNE. Disponível em: < http://www.observatoriodopne.org.br/ pne/linha-do-tempo>. Acesso em 10 abr. 2017.

2 Fonte: MEC/Inep/DEED/Sinopse do Censo Superior

3 Disponível em: <http://www.observatoriodopne.org.br/pne/linha-do-tempo>. Acesso 10 abr.2017.
} 
Entende-se que existe uma lacuna entre a titulação de mestre e o ser mestre em sala de aula. De acordo com Paulo Freire (1996, p.50), "ensinar exige consciência do inacabamento". Portanto, recém-mestres, que se veem professores, deveriam buscar formação mais específica, além da já oferecida nos cursos de pós-graduação strictu sensu, que lhes permitissem estar mais seguros, mais capacitados e aptos para dominar a arte de ensinar, caso essa tenha sido sua intenção ao ingressar no mestrado. Para Zabala (1998), qualquer educador, para melhorar sua prática educativa, não pode ser muito diferente dos outros profissionais que se movem nos campos de grande complexidade, tornando mais necessário que os professores disponham e utilizem referenciais que os ajudem a interpretar o que acontece em aula.

Ao desenvolver as três definições de mestre mais pertinentes ao tema, foram respondidos alguns questionamentos iniciais. Resta a pergunta: como desenvolver o perfil de um mestre?

\section{O perfil de um mestre}

Ao ouvir a palavra "mestre", cada pessoa deve se remeter a alguém que conheceu ou conhece que seja seu modelo de professor. Alguns pensarão em um nome de referência nacional ou internacional que tenha se destacado no meio docente ou em sua profissão. De acordo com os autores pesquisados, dentre as características necessárias para a construção do perfil de um mestre estão o conhecimento sobre o que ensinar e sobre metodologias de ensino, possuir boa oratória, ter compromisso com a aprendizagem, saber trabalhar em equipe. Einstein (1981), falando sobre educação, argumenta que, na relação que se estabelece em sala de aula, o mestre deve

"aprender a compreender as motivações dos homens, suas quimeras e suas angústias
para determinar com exatidão seu lugar exato em relação a seus próximos e à comu-
nidade. [...] é preciso, enfim, tendo em vista a realização de uma educação perfeita,
desenvolver o espírito crítico na inteligência do jovem. [...] O ensino deveria ser assim:
quem o receba, o recolha como um dom inestimável, mas nunca como uma obrigação
penosa (EINSTEIN, 1981, p. 29).

Nas palavras do físico alemão, aquilo que se aprende é o "dom inestimável". Portanto, ao tentar estabelecer o perfil de um mestre, para muitos surgirá o nome daquele que ficou consagrado como o Mestre dos mestres, o nome mais conhecido e repetido no mundo ocidental nos últimos dois mil anos: Jesus Cristo. Deixando de lado questões religiosas, parte-se do princípio de que Jesus Cristo foi um mestre sem igual, devido a uma história de vida e personalidade tão marcantes que até a contagem dos anos passou a ser feita 
em função do ano do seu nascimento.

O que fez Jesus Cristo para que fosse seguido e reverenciado até os dias de hoje? Que pedagogia foi utilizada por ele para alcançar tantos seguidores? De que maneira transmitiu seus ensinamentos para ter feito com que um pequeno grupo de doze homens despreparados propagasse sua mensagem de maneira que chegasse aos dias de hoje, perfazendo um total de mais de dois bilhões de seguidores, um terço da população mundial?

Embora não fosse um profissional do ensino, Jesus apresentou uma técnica pedagógica que serviu de base para todo o trabalho pastoral que viria a ser desenvolvido igualmente pelos seus discípulos. Seu estilo de vida, sua maneira de falar, seus gestos, seus ensinamentos, enfim, todo o seu ser, ao longo dos três anos de sua vida pública se dedicou à tarefa de ensinar, educar, formar e capacitar seus discípulos (alunos) para continuar os seus ensinamentos. A fim de demonstrar quanto o método de Jesus era inovador para sua época, e altamente eficiente, razão pela qual chegou até os dias de hoje, estabeleceu-se um paralelo entre a metodologia de Jesus e os quatro pilares do processo de aprendizagem descritos no Relatório para a UNESCO da Comissão Internacional sobre Educação para o Século XXI. ${ }^{4}$ São eles:

"Aprender a conhecer: Aprender a conhecer, combinando uma cultura geral, suficientemente ampla, com a possibilidade de estudar, em profundidade, um número reduzido de assuntos, ou seja: aprender a aprender, para beneficiar-se das oportunidades oferecidas pela educação ao longo da vida" (DELORS, 2010, p. 31).

Jesus tinha um objetivo claro, que era a Salvação da humanidade a partir da instauração do Reino de Deus no mundo. O tema central de sua mensagem era "revelar o mistério do Reino, as condições para entrar nele, e, sobretudo, o estilo de vida dos que a ele pertencem" (FLORES, 1996, p. 10). A partir dessa missão universal, o Mestre demonstrou aos discípulos as particularidades de seu método, utilizado para formar discípulos-mestres. Para que o ensino-aprendizagem pudesse ser desenvolvido com qualidade e motivação, priorizou um pequeno grupo de homens, oferecendo-lhes a possibilidade de um tratamento diferenciado, especial. Ele fez questão de caminhar junto com seus discípulos para conhecê-los melhor e para que eles também o conhecessem de perto, de tal forma que eles aprendessem seu método e pudessem transmiti-lo a outros. Cada dúvida se transformava em ensinamento.

Quando Jesus era questionado por eles, por vezes lhes respondia com

4 Educação: um tesouro a descobrir. Relatório para a UNESCO, da Comissão Internacional sobre Educação para o Século XXI. Disponível em: < http://unesdoc.unesco.org/ images/0010/001095/109590por.pdf $>$. Acesso em 20/abr/17. 
outra pergunta, para estimular seus interlocutores a trazerem à luz suas próprias ideias e, assim, conhecer-lhes o pensamento. Sua pedagogia não alimentava a passividade dos seus discípulos, mas os fazia pensar, para que eles pudessem tirar suas próprias conclusões. Em diversas ocasiões, retirou-se com eles para um lugar afastado a fim de explicar-lhes as parábolas em particular, ensiná-los a rezar. Os discípulos aprendiam com ele a compreender a realidade que os cercava e, a cada dia, aumentava o prazer de conhecer.

"Aprender a fazer, a fim de adquirir não só uma qualificação profissional, mas, de uma maneira mais abrangente, a competência que torna a pessoa apta a enfrentar numerosas situações e a trabalhar em equipe. Além disso, aprender a fazer no âmbito das diversas experiências sociais ou de trabalho" (DELORS, 2010, p. 31).

Aprender a fazer está intimamente ligado a aprender a conhecer. Jesus permitiu aos discípulos três anos de convivência, de formação. Sua metodologia de ensino estava relacionada com sua prática de vida. Jesus vivia o que pregava e pregava o que vivia, ou seja, havia coerência entre a sua maneira de viver e o que ele ensinava. "Eles ficavam pasmados com seus ensinamentos, porque falava com autoridade" (Lc 4,32). Ora, uma pessoa fala com autoridade porque vive aquilo que ensina, é coerente. O que era ensinado, na verdade, era o seu próprio estilo de vida. E, para incentivá-los a fixar o que haviam aprendido, estimulava-os a agirem por si mesmos. No Evangelho de Mateus (Cf. Mt 10,5-8) se encontra narrado que Jesus estava com seus discípulos e, ao olhar a multidão, compadeceu-se do povo que estava cansado e abatido. Naquele momento, a ação de Jesus foi despertada a partir da visão da realidade, que o impeliu a enviá-los em missão junto àquele povo sofrido, pois sabia que estavam capacitados. Mas era necessário que experimentassem por si mesmos, aprendessem fazendo, possibilitando reconhecerem suas potencialidades e limitações. "Proclamai que o Reino dos Céus está próximo. Curai os doentes, ressuscitai os mortos, purificai os leprosos, expulsai os demônios" (Mt 10,7-8). Com essas e outras recomendações, o Mestre sabia que estava diante de novos formadores.

“Aprender a conviver, desenvolvendo a compreensão do outro e a percepção das interdependências - realizar projetos comuns e preparar-se para gerenciar conflitos - no respeito pelos valores do pluralismo, da compreensão mútua e da paz” (DELORS, 2010, p. 31).

Vivendo em uma região onde diversos povos e culturas se aglomeravam, Jesus respeitava a todos os seus interlocutores e falava de forma clara para que todos entendessem. Jesus era itinerante. Percorreu quilômetros com seus 
discípulos, visitando cidades, vilarejos, com realidades sociais, econômicas e culturais distintas. Em cada uma delas, Jesus teve a oportunidade de se deparar com a dura realidade que por vezes se impunha. Jesus viveu e interagiu com os marginalizados da época: doentes (Lc 18,35-43), mulheres (Lc 8,3), crianças (Mc 10,14-16). Com atenção e respeito com todos, indiscriminadamente, resgatou-lhes a dignidade e os teve entre seus seguidores.

Seu discurso era direto, sua oratória eloquente, de maneira que, com os sacerdotes judeus do templo, se utilizava do conhecimento das Escrituras para que eles soubessem que tinha domínio sobre o assunto. Com os homens mais simples e rudes, ele falava por parábolas, utilizando, muitas vezes, acontecimentos da sua realidade social, da natureza e situações humanas cotidianas para transmitir-lhes sua mensagem.

Certamente esse item é o maior desafio dos dias de hoje, quando o individualismo se apresenta como barreira àquele que se dispõe a trabalhar em equipe. Mas o Mestre insistiu, em diversas ocasiões, que não se deve viver isolado, referindo-se com frequência a expressões como rebanho, família, povo. Ele mesmo fundou e viveu numa comunidade junto com seus doze discípulos e estabeleceu, não só com eles, mas com todos com quem conviveu, novas relações entre os indivíduos, inserindo a todos em seu plano salvífico.

"Aprender a ser, para desenvolver, o melhor possível, a personalidade e estar em condições de agir com uma capacidade cada vez maior de autonomia, discernimento e responsabilidade pessoal. Com essa finalidade, a educação deve levar em consideração todas as potencialidades de cada indivíduo: memória, raciocínio, sentido estético, capacidades físicas, aptidão para comunicar-se" (DELORS, 2010, p. 31).

Jesus sabia como suscitar nas pessoas o que elas tinham de melhor, e fazia com que elas se sentissem valorizadas, reconhecidas, acreditando em si mesmas, o que, na verdade é o que todas as pessoas anseiam. Aproveitava-se até mesmo do erro, transformando-o em aprendizado. Estava aberto, sabia escutar. Seu interesse era pela pessoa integral do discípulo, sob todos os aspectos: físico, intelectual e espiritual.

Jesus sabia ser. Nunca perdeu a chance de se aproximar das pessoas frágeis, com ideias e estilos de vida diferentes do seu, como a samaritana (cf. Jo 4,7-30), a mulher adúltera (cf. Jo 8, 3-11) e o cobrador de impostos (cf. Mt 9,9). Em cada um desses encontros, Jesus se mostrou, fê-los pensar, questionou, ensinou e resgatou a dignidade da pessoa humana. Enfim, "mais do que teorias ou doutrinas, Jesus ensinava a sabedoria de viver retamente, encontrando o sentido da existência e a forma de cumprir a própria vocação" (FLORES, 1996). Era um mestre comprometido com a sua vocação. 


\section{Considerações finais}

Ao percorrer a trajetória da reflexão sobre o que é ser mestre, pode-se perceber que o tema da Educação esteve e estará sempre em discussão, pois é um assunto que afeta todos os cidadãos que formam um país. Um dos agentes deste processo é o professor, que pode ser um mestre com ou sem titulação.

A intenção deste artigo foi suscitar a reflexão sobre o que é ser mestre nos dias de hoje, época em que os títulos de mestre e doutor se encontram tão em voga, principalmente quando a legislação praticamente os torna obrigatórios para os que querem ensinar em universidades. Por isso, não foram tecidas considerações sobre a questão financeira, que poderia levar o profissional a buscar a docência como complementação salarial; nem com relação à política educacional do país e o desrespeito com que os profissionais do ensino vêm sendo tratados. Ao tentar entender o que significa ser mestre nos dias de hoje, foram traçadas algumas considerações:

O mestre deve ser e estar, antes de tudo, comprometido com a sua vocação de ensinar. Deve estar atento às necessidades de seus alunos, buscar conhecê-los, deixando-se conhecer.

Deve estar em formação permanente, buscando conhecer novos métodos, dinâmicas e recursos tecnológicos disponíveis.

Deve saber fazer e saber ensinar a fazer.

Deve buscar a formação integral do aluno, não só como profissional, mas como ser humano.

Enfim, ser um mestre com esses atributos não deveria passar a imagem de um super-herói, mas apenas a de um profissional que ama o que faz e está sempre em busca de fazê-lo bem e melhor. Oferecer aos seus alunos o seu 'eu', sua capacidade de transferir conhecimento e seu desejo de que seus alunos o superem. Adaptando um antigo provérbio: "Bendito o mestre que consegue dar aos seus alunos raízes e asas".

Foi apresentado Jesus Cristo como o Mestre, por ter consagrado três anos de sua vida para a formação de doze homens e para transformá-los não apenas em discípulos, mas em formadores de discípulos. Esta foi a chave do sucesso da metodologia de Jesus, porque, se ele tivesse formado apenas discípulos, a sua obra não teria chegado até os dias de hoje (FLORES, 1996). $\mathrm{O}$ verdadeiro mestre não quer apenas formar alunos, mas formar formadores de alunos, ou seja, outros mestres.

\section{Referências Bibliográficas}

BÍBLIA DE JERUSALÉM. 9. ed. São Paulo: Paulus, 2001. 
DELORS, Jacques. Educação um tesouro a se descobrir. Relatório para a UNESCO da Comissão Internacional sobre Educação para o século XXI. Brasília: UNESCO, Faber-Castell, 2010. Disponível em: <http://unesdoc.unesco.org/images/0010/001095/109590por.pdf>. Acesso em 20/abr/17.

EINSTEIN, Albert. Como vejo o mundo. Rio de Janeiro: Nova Fronteira, 1981.

FLORES, José H. Prado. Formação de Discípulos. São Paulo: Loyola, 1996. (Coleção Kerygma 3).

FREIRE, Paulo. Pedagogia da Autonomia: saberes necessários à prática educativa. São Paulo: Paz e Terra, 1996.

PIMENTA, Selma G.; ANASTASIOU, Léa das Graças C. Docência do Ensino Superior. São Paulo: Cortez, 2002.

TAJRA, Sanmya Feitosa. Internet na educação: o professor na era digital. São Paulo: Érica, 2003. ZABALA, Antoni. A prática educativa: como ensinar. Porto Alegre: Artes Médicas, 1998.

Submetido em: 14-6-2017

Aceito em: 4-7-2017 